\title{
56. Communicating the climate emergency: imagination, emotion, action
}

\section{Genevieve Guenther}

Communication plays an outsize role in climate-change politics. Scientists and advocates rely on language to make climate breakdown visible, whether by projecting future catastrophes in data or by attributing our increasingly dire experience of global warming to the costs of human activities like burning fossil fuels. Yet, insofar as climate communicators want not just to educate but also to persuade voters to join the climate movement, they must do more than simply convey scientific information. As rhetoricians have known for quite literally thousands of years, communicators must appeal to the imagination, using vivid images that conjure visceral emotions, to move people to act. In the case of the climate crisis, communicators should help voters feel a complex of three specific emotions: fear of climate breakdown, outrage that powerful actors are blocking the passage of effective climate policy, and desire for a transformed global economy. Fear motivates us to protect ourselves and the people we love; outrage empowers us to experience the climate crisis as a political problem with clear antagonists; and desire enables us to accept the costs of decarbonization as greatly outweighed by the benefits of preserving the living world.

To begin with fear. All climate communicators need to do to frighten their audiences is tell the truth. But that truth should be centered on the ways that climate change will destroy our lives and the lives of our children, not on the destruction of "nature." Because "nature" is fashioned by fossil-fuel ideology as "external" to human life, the idea of its collapse in itself lacks the power to motivate large-scale political action. People need to picture their own lives or the lives of their loved ones being ruined by climate destruction before our planetary emergency will become personal for them.

Take the point, for example, that $2^{\circ} \mathrm{C}$ of warming will cause terrible things to happen all over the world: between 32 and 80 million people flooded out of their homes due to sea-level rise; over 400 million people without enough water to drink; over a billion people without the coral reefs on which they 
relied for food and sustenance. ${ }^{2}$ While voters need to know these facts (and facts like them) they need also to imagine their implications for their own daily lives. Climate communicators can describe what it will be like to have your home inundated with water at every high tide, over and over, compelling you move whether you can afford it or not. Or to be forced to stand in sweltering, endless lines to fill remarkably heavy water bottles at a public water truck because your taps have run dry. Or to have hunger gnawing at your ribs as you try to sleep because the fish that made the bulk of your diet spawned in coral reefs that have since disappeared. These smaller, more local narratives, conveyed with striking imagery, make the climate emergency tangible. The rhetorical power of climate communication arises from stories like these, which make people's suffering visible, especially when they're contextualized in the vast scale of the overarching crisis.

Scientists have not generally talked about climate change in this way. Science communication is not narrative and vice versa. But climate scientists have become increasingly willing to allow writers, activists, and politicians to use emotive and literary language to describe the human costs of fossil fuels. ${ }^{3}$ Scientists should continue to support artful representations of climate horrors, and on their part embrace a risk-communication framework that includes the fat-tail effects of different degrees of warming, precisely because the damage from those effects would be so devastating even if the likelihood of their occurrence is less than 95 percent. For many years, the social science research was taken to show that scaring people about climate change was counterproductive, but in fact the original research argues that fear can be motivating when balanced by a sense of agency.

The mistaken consensus about fear in climate communication was grounded in an incomplete reading of Saffron O'Neill and Sophie Nicholson-Cole's "'Fear won't do it': promoting positive engagement with climate change through visual and iconic representations" (2009). The study on which this paper was based did establish that showing decontextualized images of the natural world ravaged by climate change to "young mothers from a deprived area, young professionals between the ages of 26 and 35, and high school students" (p. 365) ultimately distanced people in those particular groups from the human causes of climate breakdown, decreasing the issue saliency of climate change for them overall. From this and another image-based survey conducted with participants already engaged in climate advocacy, O'Neill and Nicholson-Cole surmised that "fear may be an inappropriate tool for climate change communication" (p. 376). Yet, the paper itself offers a more nuanced conclusion than this surmise alone provides, for it clarifies that it is only "on a stand-alone basis" that fear has "a "negative' impact on active engagement with climate change" (ibid.; my emphasis), and it ultimately recommends that "dramatic representations [meant to frighten listeners] must be partnered with 
those that enable a person to establish a sense of connection with the causes and consequences of climate change...so that they can see the relevance of climate change for their locality and life and see that there are ways in which they (and others) can positively respond" (ibid.).

To show voters how they can "positively respond" to the threat of the climate crisis, climate communicators should refrain from concluding their messages with the reassurance that technical solutions to the climate crisis exist. This reassurance fails to tell audiences what they can do personally to build the political coalition that will force governments to pass adequate climate policies. Worse, it inaccurately suggests that technological progress will make everything turn out all right. ${ }^{4}$ Communicators should instead conclude their narratives by offering suggestions for political actions that collectively will produce systems change, while acknowledging that embracing these actions will require a good deal of emotional courage to confront climate breakdown as well as faith that change through politics is possible and worthwhile fighting for. ${ }^{5}$

This prescription might seem to lead scientists onto the shoals of political advocacy, where the authority of scientific objectivity runs aground. But it's simply the case that this round of planetary climate change is caused by human activity, which means that politics is an element of the scientific problem. The argument that scientists should refrain from discussing the organized human behavior causing our current global warming is a political ploy to keep the scientific justification for decarbonization out of the discourse of the climate movement. And in all events, any possible method of science communication has already been politicized. Even climate scientists' efforts to be judicious and objective have been weaponized by the merchants of doubt. Take, for instance, the denialist campaign to distort the concept of scientific uncertainty. ${ }^{6}$ For decades, deniers have argued that climate scientists are too uncertain about climate change to justify the economic costs of abatement. Their claims have confused the public and delayed the implementation of climate policy at least in part because most people are largely unfamiliar with the scientific meaning of "uncertainty." Instead of hearing that scientists have identified a range of outcomes that they can project with confidence, voters hear the message that climate scientists are unsure whether climate change is real or dangerous. So when scientists attempt to be apolitical, hedging against accusations of alarmism by highlighting the "uncertainty" of their research, they unwittingly suggest that they're unsure about their own science and thereby reinforce the deniers' production of doubt. There is no pure scientific communication in a social field where climate change is politically contested. In light of this reality, scientists can best establish their objectivity by acknowledging the political context in which their speech circulates (ironically enough). This is why social science research shows that scientists can augment the authority of 
their communication by "inoculating" their audiences against denialist messaging before conveying scientific facts. ${ }^{7}$

Inoculation works because it brings the conversation back to politics and human agency. Too often, communicators represent climate change as a disembodied force that we should fight directly, when in reality we must fight the people in power who are supporting the fossil-fuel economy and blocking decarbonization. The fight against these people is best fueled by outrage - the second of the three most powerful emotions produced by effective climate communication. While climate communicators should seek to produce such outrage, they need not be histrionic to do so. Simply describing the appalling moral choice that the powerful are making, as Greta Thunberg does with such stark clarity, is enough. ${ }^{8}$ Nor need this moral outrage be compromised by the fact that everyone in the fossil-fuel economy produces greenhouse-gas pollution to some degree. The practices of individual subjects are constrained by their systemic contexts; living in the world as it is now means participating in networks of activity that produce carbon dioxide. Yet, even within those constraints there are degrees of responsibility, ranging from the utter innocence of the over six billion people who live on less than ten dollars a day and emit almost no $\mathrm{CO}_{2}$, through the complacency of the top 10 percent of people who produce 50 percent of annual global emissions, to the deep and shameful complicity of, for example, the many in the news media who refuse to mention climate change even in the stories about its disasters they're already reporting. ${ }^{9}$ It is tempting to universalize the practices that lead to climate change, or, worse, characterize climate change as an expression of "human nature." But we must resist that temptation and keep both synchronic and diachronic perspectives of the crisis in view: humanity is stratified, both within nations and across the globe, not everyone is equally responsible for climate change, fossil-fuel executives and politicians have colluded to lead us to this terrifying moment, ${ }^{10}$ and they continue to maintain genocidal energy policies while the climate emergency becomes ever more deadly with each passing day. What these executives and politicians are doing is evil and should be described as such.

But in order to communicate this moral outrage effectively, climate communicators need to make our commitment to changing the world clear. To the greatest possible degree, we need ourselves to stop consuming fossil fuels for pleasure. (Please ask yourself: would Greta Thunberg have been as effective if she had flown around Europe making her speeches?) Communicators with low-carbon footprints are more effective for three reasons. First, social-science research shows that climate-change communicators with small carbon footprints are seen as more trustworthy by their audiences. ${ }^{11}$ Second, by performing their personal decision to decarbonize their own lives, such communicators convey that climate change is an emergency worth giving up fossil-fuel 
consumption to address (thereby short-circuiting the dreaded bystander effect, in which everyone waits to see their neighbor act before acting themselves). ${ }^{12}$ Third, and perhaps most importantly, communicators who make low-carbon choices enable people to envision meaningful fossil-free lives, not marked by austerity but filled with deep local pleasures and lofty overarching significance. We don't have to be saints to be correct about atmospheric chemistry, of course, but to move people into action, communicators must offer their audiences more than bare facts. We must show them something to hope for.

Communication meant to move people to action solicits what literary criticism calls "identification": the experience of projecting oneself on to narrative characters and envisioning a different version of oneself in an imaginary context. ${ }^{13}$ It does not simply "frame" campaigns for climate policy in terms of the co-benefits of decarbonization. ${ }^{14}$ The style of climate communication for which I've argued here helps audiences to identify themselves with the victims of climate change, to see fossil-fuel barons and climate-denying politicians as villains, and to understand themselves as people, connected to a cause with species-defining significance, who courageously transform their priorities and band together with others to create a new world. In other words, this style of communication activates the cultural memory of a very old and powerful literary genre: that of the epic, in which the hero draws on his skill, virtue, and cunning to fight against great odds, save his household, and found a new era. From David who ingeniously describes how to topple Goliath, to Aeneas who perseveres in his duty despite the temptations of pleasure, to the band of rebels in Star Wars who build a coalition of misfits to topple the Empire, models for imagining the fight to end the fossil-fuel economy against great odds are there to be deployed. Changing people's minds requires not just iterating bare facts but also offering concrete actions and inspiring the belief in personal agency that can be devoted to the collective production of a habitable world. There is no greater task for climate-change communicators now than telling the stories that will bring that world into being.

\section{NOTES}

1. See Van der Linden, Maibach and Leiserowitz (2015, p. 759): "Information about climate change risks needs to be translated into relatable and concrete personal experiences." See also Corner and Clark (2017, p. 53): "People are more likely to be willing to act on climate change if they think that it will impact them (or people they care about and who are similar to them) in the near future."

2. See Intergovernmental Panel on Climate Change (IPCC) (2018).

3. Compare, for instance, the changed reaction of the scientific community to the publication of the monograph The Uninhabitable Earth (2019) by the American journalist David Wallace-Wells. When in 2017 Wallace-Wells published the article that he later expanded into the book, he was criticized by many climate 
scientists for using literary devices like hyperbole and amplification to frighten people with exaggerations of the dangers of climate breakdown. See Climate Feedback (2017). The publication of his book 18 months later, by contrast, went uncontested, suggesting that these same scientists no longer felt the need to attack the method of underscoring the terrors of climate change with rhetorical and literary devices.

4. For a study showing that complacency is increased by communication centering on the reduction of emissions due to technological progress (what the paper calls "an optimistic message"), see Hornsey and Fielding (2016).

5. My model of "political action" relies on a bifold conception of "politics" in democratic regimes. On the one hand, "politics" includes all actions that culminate in the passing and enforcement of legislation - everything from campaigning, lobbying, debating, and voting, to governmental procedures, to persuading, striking, organizing, and so on. On the other hand, "politics" also includes what Chantal Mouffe (2005) calls "agonism" within "a common symbolic space" (p. 20), an agonism inflected by "hegemonic practices" that bestow social power on certain identities and institutions within that space. In this conception of politics, "every hegemonic order is susceptible to being challenged by counter-hegemonic practices, ie. practices which will attempt to disarticulate the existing order and install another form of hegemony" (p. 18). Brulle and Norgaard (2019) elaborate this conception of the political in the sphere of climate action by envisioning "actions at the individual level to reshape the self and the daily habitus, at the institutional level to revise or invent new collective routines of action, and at the ideological level to support social movements that seek to advance alternative ideological frameworks to guide social action" (p. 904).

6. See Oreskes and Conway (2010). In subsequent research, Oreskes demonstrates that the political misuse of the concept of scientific uncertainty extends back even to 1920s' US debates over making electricity a public good. See Oreskes (2015).

7. See Cook (2019) and Cook, Lewandowsky and Ecker (2017).

8. See Thunberg (2019).

9. Oxfam (2015). For data on the US broadcast media's nearly ubiquitous silence on climate change in 2019, see Macdonald, Fisher and Cooper (2020).

10. See Banerjee, Cushman and Hasemyer (2015) and Supran and Oreskes (2017).

11. See Attari, Krantz and Weber (2016, 2019); Westlake (2018); and Thompson (2011).

12. See Griskevicius, Cialdini and Goldstein (2008); Cialdini (1984), Ch. 4; Cialdini and Goldstein (2004); and Darley and Latané (1968). See also Brulle and Norgaard (2019), p. 904: "Transforming existing organizational practices...is dependent on the creation of social imaginaries that generate the cultural resources to envision variations in practice."

13. The insight that stories inspire identification is ancient, advanced by Plato in Books III and X of his Republic as the justification for banishing poets from his ideal city, lest they inspire youth to identify with and imitate their licentious representations of the gods. This power of poetry to inspire emulation became praiseworthy in the literary theory of the Renaissance - see, for instance, Sir Philip Sidney's The Defense of Poesie - and continues even now to motivate justifications for literary education. For a modern, ironic reworking of the idea, see, for example, Girard (1965).

14. For an example of this approach, see Maibach et al. (2010). 


\section{REFERENCES}

Attari, Shazeen Z., David H. Krantz and Elke U. Weber (2016), "Statements about climate researchers' carbon footprints affect their credibility and the impact of their advice," Climatic Change, 138 (1-2), 325-38.

Attari, Shazeen Z., David H. Krantz and Elke U. Weber (2019), "Climate change communicators' carbon footprints affect their audiences' policy support," Climatic Change, 154, 529-45.

Banerjee, Neela, John H. Cushman Jr., and David Hasemyer (2015), Exxon: The Road Not Taken, Brooklyn, NY: Inside Climate News.

Brulle, Robert J. and Kari Marie Norgaard (2019), "Avoiding cultural trauma: climate change and social inertia," Environmental Politics, 28 (5), 886-908.

Cialdini, Robert B. (1984), Influence: The Psychology of Persuasion, New York: William Morrow.

Cialdini, Robert B. and Noah J. Goldstein (2004), "Social influence: compliance and conformity," Annual Review of Psychology, 55, 592-621.

Climate Feedback (2017), "Scientists explain what New York Magazine article on 'The Uninhabitable Earth' gets wrong," 9 July, accessed 15 March 2020 at https:// climatefeedback.org/evaluation/scientists-explain-what-new-york-magazine-article -on-the-uninhabitable-earth-gets-wrong-david-wallace-wells/.

Cook, John (2019), "Understanding and countering misinformation about climate change," in Innocent Chiluwa and Sergei A. Samoilenko (eds), Handbook of Research on Deception, Fake News, and Misinformation Online, Hershey, PA: IGI-Global, pp. 281-306.

Cook, John, Stephan Lewandowsky and Ullrich K.H. Ecker (2017), "Neutralizing misinformation through inoculation: exposing misleading argumentation techniques reduces their influence," PLOS ONE, 12 (5), e0175799.

Corner, Adam and Jamie Clark (2017), Talking Climate: From Research to Practice in Public Engagement, Cham, Switzerland: Palgrave Macmillan.

Darley, John M. and Bibb Latané (1968), "Bystander intervention in emergencies: diffusion of responsibility," Journal of Personality and Social Psychology, 8 (4), 377-83.

Girard, René (1965), Deceit, Desire, and the Novel: Self and Other in Literary Structure, Baltimore, MD: Johns Hopkins University Press.

Griskevicius, Vladas, Robert B. Cialdini and Noah J. Goldstein (2008), "Social norms: an underestimated and underemployed lever for managing climate change," accessed 23 March 2020 at https://pdfs.semanticscholar.org/8791/b3ce170ee1328 adb2df83d75c36fdad326e9.pdf.

Hornsey, Matthew J. and Kelly S. Fielding (2016), “A cautionary note about messages of hope: focusing on progress in reducing carbon emissions weakens mitigation motivation," Global Environmental Change, 39, 26-34.

Intergovernmental Panel on Climate Change (IPCC) (2018), Special Report on Global Warming of $1.5^{\circ} \mathrm{C}$, Geneva: IPCC.

Macdonald, Ted, Allison Fisher and Evlondo Cooper (2020), "How broadcast TV networks covered climate change in 2019," MediaMatters.org, 27 February, accessed 23 March 2020 at https://www.mediamatters.org/broadcast-networks/how-broadcast -tv-networks-covered-climate-change-2019. 
Maibach, Edward, Matthew Nisbet and Paula Baldwin et al. (2010), "Reframing climate change as a public health issue: an exploratory study of public reactions," BMS Public Health, 10 (1), 299-309.

Mouffe, Chantal (2005), On the Political, London: Routledge.

O'Neill, Saffron and Sophie Nicholson-Cole (2009), "Fear won't do it': promoting positive engagement with climate change through visual and iconic representations," Science Communication, 30 (3), 355-79.

Oreskes, Naomi (2015), "The fact of uncertainty, the uncertainty of facts and the cultural resonance of doubt," Philosophical Transactions of the Royal Society A: Mathematical, Physical, and Engineering Sciences, 373 (2055), 20140455.

Oreskes, Naomi and Erik Conway (2010), Merchants of Doubt: How a Handful of Scientists Obscured the Truth on Issues from Tobacco Smoke to Global Warming, New York: Bloomsbury.

Oxfam (2015), "Extreme carbon inequality: why the Paris climate deal must put the poorest, lowest emitting and most vulnerable people first," Oxfam Media Briefing, 2 December, accessed 23 March 2020 at https://oi-files-d8-prod.s3.eu-west -2.amazonaws.com/s3fs-public/file_attachments/mb-extreme-carbon-inequality -021215-en.pdf.

Plato (1992), Republic, trans. G.M.A. Grube, Indianapolis, IN: Hackett.

Sidney, Sir Philip (2004), The "Defense of Poesy" and Selected Renaissance Literary Criticism, ed. Gavin Alexander, London: Penguin.

Supran, Geoffrey and Naomi Oreskes (2017), "Assessing ExxonMobil's climate change communications (1977-2014)," Environmental Research Letters, 12 (8), 23 August, accessed 23 March 2020 at https://iopscience.iop.org/article/10.1088/1748 $-9326 /$ aa815f.

Thompson, Edward (2011), "Making our actions consistent with our scientific predictions," Weather, 66, 195.

Thunberg, Greta (2019), No One is Too Small to Make a Difference, New York: Penguin.

Van der Linden, Sander, Edward Maibach and Anthony Leiserowitz (2015), "Improving public engagement with climate change: five 'best practice' insights from psychological science," Perspectives on Psychological Science, 10 (5), 758-63.

Wallace-Wells, David (2019), The Uninhabitable Earth: Life After Warming, New York: Tim Duggan Books.

Westlake, Steve (2018), "A counter-narrative to carbon supremacy: do leaders who give up flying because of climate change influence the attitudes and behaviour of others?" unpublished MSc dissertation, Birkbeck University, London. 